\title{
Role of Sweat in Accumulation of \\ Orally Administered Griseofulvin in Skin
}

\author{
Vinod P. Shah, William L. Epstein, and Sidney Riegelman \\ From the Department of Pharmacy, School of Pharmacy, and the Department \\ of Dermatology, School of Medicine, University of California, \\ San Francisco, California 94143
}

\begin{abstract}
A в S T R A C T Griseofulvin, an orally effective antimicrobial agent, appears in the stratum corneum within 4-8 $\mathrm{h}$ after oral administration. Griseofulvin distribution was found to be highest in the outermost layers of the stratum corneum (level I, $20.8 \pm 1.5 \mathrm{ng} / \mathrm{mg}$ ) and lowest inside (level II, $10.0 \pm 1.5$; level III, $7.5 \pm 2.2 \mathrm{ng} / \mathrm{mg}$ ). In order to study the precise mechanism of griseofulvin transfer to stratum corneum, the role of sweat in the accumulation of griseofulvin was considered. Heat-induced total body sweating decreased the mean stratum corneum concentration of griseofulvin by $55 \%$, and 200-300 $\mathrm{ng}$ of griseofulvin accumulated per $\mathrm{ml}$ of sweat. A silicone hydrophobic resin was used to differentiate between "wash-off" and carrier properties of sweat for griseofulvin. Prevention of transepidermal water and sweat loss by (a) topical application of formaldehydereleasing cream to one palm, (b) occlusion by a $2 \times 2$ $\mathrm{cm}$ patch on one arm, and $(c)$ wearing a rubber glove for $24 \mathrm{~h}$, showed a lower griseofulvin concentration when compared to control areas in the same subjects. The results of the gloved hand experiment show that a complete equilibrium is established at all three levels of stratum corneum, thereby removing the reversed gradient. These results support the hypothesis that a "wick effect" is responsible for the observed reversed drug gradient within the stratum corneum. The results of the experiments suggest that sweat and transepidermal fluid loss play an important role in griseofulvin transfer in stratum corneum.
\end{abstract}

Presented at the Western Section on Dermatology, American Federation of Clinical Research, Carmel, Calif., in February 1972 and at the Society of Investigative Dermatology of the European Society of Dermatological Research, Amsterdam, Holland, in May 1972.

Received for publication 6 September 1973 and in revised form 10 December 1973.

The Journal of Clinical Investigation Volume 53 June 1974·1673-1678

\section{INTRODUCTION}

Griseofulvin is an orally effective antimicrobial agent for superficial fungal infections of the skin. Exactly how griseofulvin concentrates in the skin is not understood. Indeed, little is known about the rate and degree of tissue uptake of drugs into the skin, since conventional studies on drug disposition usually ignore the skin, or more specifically, the epidermis, as a compartment. Since this epidermis is an avascular tissue and is the site of action for griseofulvin, it warrants examination as to what mechanisms are involved in the accumulation and removal processes. The availability of a very sensitive gas-liquid chromatography assay (1) for measuring griseofulvin at drug levels of $1 \times 10^{-10} \mathrm{~g}(100 \mathrm{pg})$ made feasible the study of the concentration time-course of griseofulvin in milligram samples of epidermal tissue. A skin-scraping method was devised to obtain three tissue samples at distinct levels of stratum corneum from which griseofulvin levels could be analyzed (2). By using these tools, it was found that contrary to earlier. reports (3), griseofulvin appeared in the stratum corneum within $4-8 \mathrm{~h}$ after initial oral administration of the drug $(1,2)$. In addition, the drug appeared in the highest concentration in the outermost layers of the stratum corneum (level I) and in the lowest concentration in the innermost level (level III), producing a gradient of level I > level II > level III.

It was also noted that the buildup of griseofulvin in skin is dependent on climate, the concentration reaching levels three to four times higher in summer than in winter, presumably because of greater water loss in hot weather (2). Further, griseofulvin was collected on occluded patches, which indicates that the drug can be transferred out of the horny layer by sweat and other exudates. 
These findings at first seemed paradoxical if one presumes that griseofulvin is delivered to the stratum corneum by a diffusion gradient initiated at the capillary bed and is carried to the surface via the intercellular fluids. This should result in a diffusion gradient in which the concentration of drug should be reversed, i.e., level III $>$ level II $>$ level I. To explain the paradox, it was postulated that the evaporation of sweat or transepidermal (extracellular) fluids from the skin surfaces may have caused a deposition of nonvolatile solutes, including griseofulvin in superficial layers which results in a higher concentration of drug towards the periphery, which produces a so-called "wick effect." These observations of $(a)$ a wick effect" ( $b$ ) the higher buildup of drug concentration in the summer, and $(c)$ presence of drug in occlusive patches, suggested that sweat may play a significant role in griseofulvin transfer to and from the horny layers. This papers reports a systematic study of the role of sweat in the accumulation of griseofulvin in the skin.

\section{METHODS}

Healthy male volunteers served as subjects and were divided into groups according to the design of each experiment. All subjects received $0.5 \mathrm{~g}$ micronized griseofulvin tablets (Grisactin, Ayerst Laboratories, New York) at intervals of $12 \mathrm{~h}$. One and two or three levels of skin samples, each weighing 1-3 mg, were collected by scraping with a large open dermal curet. Details of scraping techniques have been described (2). With the scrapings, blood samples were drawn and allowed to clot, and serum was separated. Experiments were designed to study the effect of sweat, dehydration, and hydration on griseofulvin concentration of the stratum corneum at different levels.

Sweat experiment. The effect of heat-induced sweat was studied in three subjects. The subjects were given one tablet of griseofulvin twice a day for 3 days. To collect total body sweat, the subjects were covered with plastic bags and subjected to the hot dry air of a sauna bath for 15-20 min every day. The sweat collected in the plastic bags was frozen until analysis. Griseofulvin concentration was determined also in skin and plasma, before and after sweating, and in sweat.

In order to differentiate between "wash-off" and carrier properties of sweat for griseofulvin, an attempt was made to collect sweat before it came in contact with the skin and thereby reduce the amount of griseofulvin leached off from the cells surrounding the duct. Four subjects were given three tablets of griseofulvin at intervals of $12 \mathrm{~h}$. The sweat gland imprint technique of Harris, Polk, and Willis (4) was modified to collect sweat from the forehead. A silicone hydrophobic resin was prepared by intimately mixing about $2 \mathrm{ml}$ of base elasticone and two drops of accelerator elasticone (Type II, Silicone Base, Kerr Manufacturing Co., Romulus, Mich.) just before application. Sweating was stimulated in four subjects; the forehead was dried and a thin film of silicone hydrophobic resin applied on half the forehead. The other half served as a control. Sweating was stimulated again. The hydrophobic silicone withdrew wherever sweat droplets emerged from sweat duct ostia, which resulted in small holes at the points of sweat delivery to the surface. Sweat from the silicone- treated and a control area on the forehead was collected by micropipets and analyzed for griseofulvin.

Topical dehydration experiment. The palmar stratum corneum was relatively dehydrated in eight subjects by four daily applications of $15 \%$ formaldehyde-releasing cream to one palm. This produced a clinically dry palm and hypohidrosis, as measured by starch iodine imprint method (5). The other palm served as a control. After 4 days of application, three tablets of griseofulvin were given at intervals of $12 \mathrm{~h}$. Two- or three-level skin scrapings from both palms werè obtained and analyzed for griseofulvin content.

Hydration experiment. Hydration of the stratum corneum was achieved in two ways: $(a)$ one hand was covered with a rubber glove and sealed with a plastic tape for $24 \mathrm{~h}$ in nine subjects receiving griseofulvin; $(b)$ an area on the forearm was occluded with a $2 \times 2-\mathrm{cm}$ cotton gauze patch and further covered with Saran and tape wrapping for $24 \mathrm{~h}$ in six subjects receiving griseofulvin. The uncovered palm and a nonoccluded area served as a control in each subject. These procedures reduced or prevented transepidermal water and sweat loss during griseofulvin treatment, which resulted in a hydration of the stratum corneum. All the subjects received three tablets of griseofulvin. Two- or three-level scrapings were used for analysis.

\section{Assay}

Griseofulvin concentration in skin was determined by gas-liquid chromatography using ${ }^{83} \mathrm{Ni}$ electron capture detector and diazepam as an internal standard on a 6-ft column packed with 3\% OV-17 Gas-chrom Q (Applied Science Labs, Inc., State College, Pa.). Serum and sweat levels of griseofulvin were determined by using a spectrophotofluorometric method, using $300 \mathrm{~nm}$ as activation and $420 \mathrm{~nm}$ as fluorescence wavelengths in methanol-water, $1: 1$. Technical details of both assays have been described (1). The glove was suspended in $50 \mathrm{ml}$ water and shaken in an ultrasonic for $5 \mathrm{~min}$. Griseofulvin from water was then extracted with ether. In the case of the patch, drug was directly extracted with ether. The ether layer, in both cases, was washed with $10 \%$ bicarbonate solution and water. The ether was then evaporated to dryness, and the amount of griseofulvin was determined spectrofluorometrically. In cases where only a small quantity of sweat was collected, i.e., from the forehead using a micropipet, $0.1 \mathrm{ml}$ of sweat was treated with $1 \mathrm{ml}$ of $5 \%$ sodium bicarbonate, extracted with ether, and analyzed by gas chromatography.

\section{RESULTS}

Sweat experiments. The results of heat-induced sweating are shown in Table $I$ and the data are graphically represented in Fig. 1. The griseofulvin levels in skin decreased markedly, on an average of $50-60 \%$ after sweating. Plasma levels were not significantly affected by sweating. The concentration of griseofulvin in sweat remained remarkedly constant, between 200 and $300 \mathrm{ng} /$ $\mathrm{ml}$ in all cases, independent of the total volume of sweat, which varied between 75 and $300 \mathrm{ml}$.

The griseofulvin concentration in sweat recovered from the silicone film-occluded area and the control areas are shown in Table II. Griseofulvin concentration in sweat from the protected area varied between 133 and 
TABLE I

Effect of Sweat on Palmar Skin and Serum Concentration of Griseofulvin

\begin{tabular}{|c|c|c|c|c|c|c|c|c|c|}
\hline \multirow[b]{3}{*}{ Day. . } & \multicolumn{9}{|c|}{ Subjects } \\
\hline & \multicolumn{3}{|c|}{$\mathrm{Ca}$} & \multicolumn{3}{|c|}{$\mathrm{Da}$} & \multicolumn{3}{|c|}{$\mathbf{M a}$} \\
\hline & 1st & 2nd & 3 rd & 1st & 2nd & $3 r d$ & 1st & 2nd & 3 rd \\
\hline Serum before sweat, $\mu g / m l$ & 1.56 & 0.99 & 0.74 & 1.48 & 0.96 & 0.80 & 1.76 & 1.76 & 0.8 \\
\hline Serum after sweat, $\mu g / m l$ & 1.45 & 0.99 & 0.82 & 1.50 & 0.91 & 0.85 & 1.98 & 1.46 & 0.42 \\
\hline Skin before sweat, $n g / m g$ & 2.65 & 3.95 & 1.33 & 8.17 & 10.02 & 6.57 & 7.82 & 8.26 & 6.53 \\
\hline Skin after sweat, $n g / m g$ & 0.20 & 0.70 & 0.97 & 3.10 & 6.89 & 2.47 & 4.41 & 2.52 & 3.21 \\
\hline Sweat, vol $m l$ & 275 & 300 & 250 & 100 & 75 & 190 & 90 & 200 & 225 \\
\hline Sweat concn., $n g / m l$ & 290 & 250 & 200 & 340 & 260 & 250 & 300 & 260 & 320 \\
\hline Total sweat, $\mu g$ & 79.7 & 75.0 & 50.0 & 33.5 & 19.5 & 46.6 & 26.6 & 52.0 & 72.0 \\
\hline
\end{tabular}

$445 \mathrm{ng} / \mathrm{ml}$ and from the control area between 289 and $585 \mathrm{ng} / \mathrm{ml}$. These results indicate that griseofulvin can be dissolved in sweat and thereby is carried to the stratum corneum; but at the same time, profuse sweating can wash griseofulvin off the skin surface.

Topical dehydration experiment. The effect of formaldehyde-releasing cream on the palmar skin is shown in Table III. Six of the eight subjects responded fully to formaldehyde and its tanning activity; the other two failed to respond completely, as ascertained by the iodine imprint method (5). The results indicate that those individuals showing the greatest anhidrotic effect from the cream also had the lowest concentration of drug in levels I, II, and III of the palmar horny layer compared

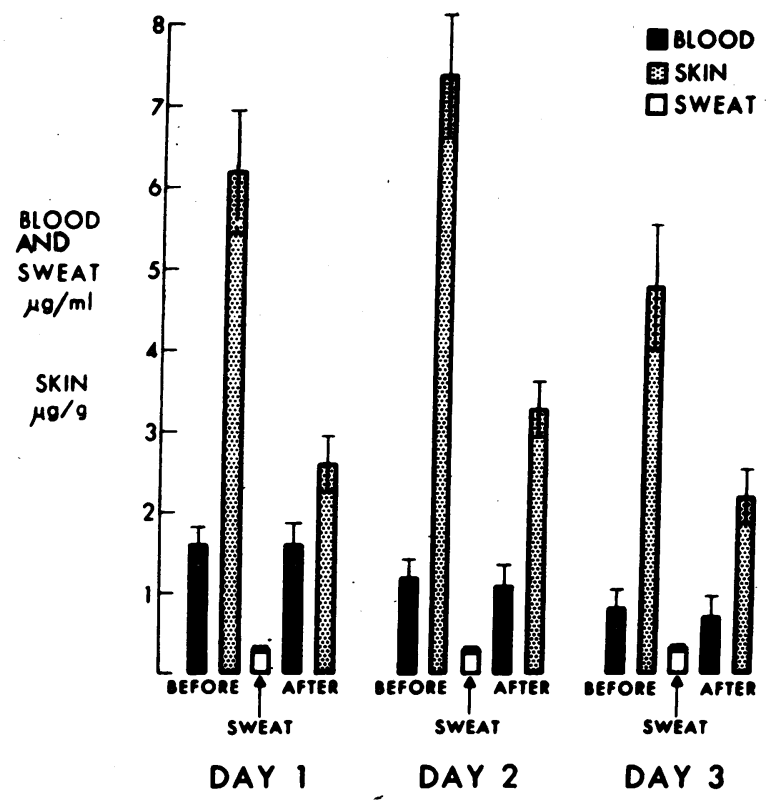

Figure 1 Effect of sweat on plasma and skin levels of griseofulvin. The data represent an average of three subjects on 3 days, while taking $500 \mathrm{mg}$ griseofulvin twice a day. to the control, but all still retained the "reversed gradient" pattern. The differences seen in the values found at levels I and II were significant at a level of $P<0.05$. Since formalin reduced sweat, these results can be interpreted to mean that sweat delivery of griseofulvin is important in determining the concentration of drug in stratum corneum.

Hydration experiment. The effect of hydration of stratum corneum by an occlusive patch or rubber glove on griseofulvin concentration is portrayed in Tables IV and V. Occlusion (Table IV) caused a significantly lower concentration of griseofulvin to appear in the occluded area compared to the control at both levels tested. The reverse gradient in the control area was maintained, but in the occluded area, four of six subjects showed an equilibrium between the two levels. The occlusive patch contained 50-200 ng of griseofulvin.

Gloved occlusion (Table V) produced a markedly lower concentration of griseofulvin in the gloved hand of all subjects compared to the control palm, representing an average drop in griseofulvin concentration of $60-75 \%$ at all levels of the occluded hand. A total of $40-700 \mathrm{ng}$ of griseofulvin was detected in the glove. This wide variation of griseofulvin concentration in the glove may depend upon individual differences in sweat-

TABLE II

Griseofultin Concentration in Sweat Samples Collected under Profuse Sweating

\begin{tabular}{llcc}
\hline Subject & $\begin{array}{c}\text { Treated } \\
\text { forehead* }\end{array}$ & $\begin{array}{c}\text { Control } \\
\text { forehead }\end{array}$ \\
\hline & \multicolumn{2}{c}{${ }^{n g / m l}$} \\
$\mathrm{De}$ & 133 & 289 \\
$\mathrm{Si}$ & 265 & 315 \\
$\mathrm{Mo}$ & 230 & 315 \\
$\mathrm{Tr}$ & 445 & 585 \\
\hline
\end{tabular}

* Sweat collected after applying silicone hydrophobic elastomer. 
TABLE III

Effect of Topical Dehydration on Griseofulvin Concentration of Palmar Stratum Corneum by Using $15 \%$ Formaldehyde-Releasing Cream

\begin{tabular}{|c|c|c|c|c|c|c|}
\hline \multirow[b]{2}{*}{ Subject } & \multicolumn{3}{|c|}{ Control palm } & \multicolumn{3}{|c|}{ Anhidrotic palm } \\
\hline & $I^{*}$ & II* & III* & $\mathrm{I}^{*}$ & II* & III* \\
\hline & \multicolumn{3}{|c|}{$n g / m g$} & \multicolumn{3}{|c|}{$n g / m g$} \\
\hline Ed & 13.9 & 3.4 & & 6.4 & 1.9 & \\
\hline $\mathrm{Ha}$ & 10.5 & 6.4 & & 11.2 & 6.7 & \\
\hline $\mathrm{Ha}$ & 16.6 & 8.7 & & 4.1 & 0.7 & . \\
\hline Sh & 13.5 & 10.4 & & 7.2 & 4.9 & \\
\hline $\mathrm{Sh}$ & 37.6 & 14.5 & & 13.7 & 9.8 & \\
\hline $\mathrm{Bi}$ & 21.4 & 14.1 & 4.4 & 4.7 & 1.8 & 0.4 \\
\hline $\mathrm{Ha}$ & 15.7 & 10.7 & 10.7 & 13.1 & 10.7 & 3.7 \\
\hline Wi & 58.0 & 22.5 & 19.2 & 37.1 & 15.8 & 1.3 \\
\hline Mean \pm SE & $23.4 \pm 5.8$ & $11.3 \pm 2.1$ & $11.4 \pm 4.3$ & $12.2 \pm 3.8$ & $6.5 \pm 1.9$ & $1.8 \pm 1.0$ \\
\hline
\end{tabular}

* These refer to the arbitrarily defined stratum corneum levels: the outermost 10-20 stratum corneal layers as level I, the intermediate 20-30 layers as level II, and the innermost 8-10 layers with stratum lucidum as level III.

ing. Rubber glove occlusion resulted in equilibrium of griseofulvin concentration at all three levels of stratum corneum, thereby removing the gradient effect. The reverse gradient, however, was still maintained in the control palm. The values of the control and treated areas and palm at levels I and II are significant at a level of $P<0.05$. These results are interpreted to mean that hydration results in equilibrium of fluids between different levels, abolishing the wick effect.

\section{DISCUSSION}

Earlier studies showed that griseofulvin distributes preferentially in the most superficial layers of stratum corneum $(1,2)$. The average griseofulvin concentration found in 38 subjects was $20.8 \pm 2.5 \mathrm{ng} / \mathrm{mg}$ tissue in the outermost level I, $10.9 \pm 1.5 \mathrm{ng} / \mathrm{mg}$ in level II, and $7.5 \pm$ $2.2 \mathrm{ng} / \mathrm{mg}$ in level III. The experiments reported here demonstrate that sweat acts as a carrier for griseofulvin and that profuse sweating can wash griseofulvin off the skin surface. Griseofulvin is very insoluble in water $\left(14 \mu \mathrm{g} / \mathrm{ml}\right.$ at $\left.37^{\circ} \mathrm{C}\right)$ and is protein bound to approximately $85 \%$. Thus, at the usual range of plasma drug levels of $1-3 \mu \mathrm{g} / \mathrm{ml}$, the drug concentration in plasma water should reach $150-450 \mathrm{ng} / \mathrm{ml}$. The data in Table I indicate that the sweat concentration ranged from 200 to $340 \mathrm{ng} / \mathrm{ml}$. While it did not exactly correlate with the proposed plasma water concentrations for these subjects, the sweat is exposed to tissues at initially higher levels, and it clearly could elute drug from the tissue depot.

Several groups of investigators have measured sweat levels of drugs and compared them to blood or urine levels (6-9). Although the precise mechanism of sweat excretion remains unknown, it is generally thought it

TABLE IV

Effect of Hydration on Griseofulvin Concentration of Stratum Corneum-Occlusive Patch Experiment

\begin{tabular}{|c|c|c|c|c|c|}
\hline \multirow[b]{2}{*}{ Subject } & \multicolumn{2}{|c|}{ Controlled area } & \multicolumn{2}{|c|}{ Occluded area } & \multirow{2}{*}{$\begin{array}{l}\text { Griseofulvin } \\
\text { in patch }\end{array}$} \\
\hline & $I^{*}$ & II* & $\mathrm{I}^{*}$ & II* & \\
\hline & \multicolumn{2}{|c|}{$n g / m g$} & \multicolumn{2}{|c|}{$n g / m g$} & $n g$ \\
\hline Go & 28.9 & 26.2 & 15.4 & 10.5 & 110 \\
\hline $\mathrm{He}$ & 28.9 & 6.7 & 18.4 & 10.8 & 190 \\
\hline $\mathrm{Ni}$ & 32.4 & 26.9 & 14.3 & 12.0 & 150 \\
\hline Po & 24.2 & 14.1 & 5.1 & & 50 \\
\hline Mo & 28.9 & 28.4 & 5.8 & 6.9 & 200 \\
\hline $\operatorname{Tr}$ & 40.0 & 13.7 & 8.2 & 9.3 & 190 \\
\hline Mean \pm SE & $29.6 \pm 2.2$ & $20.35 \pm 4.1$ & $11.2 \pm 2.2$ & $10.3 \pm 0.5$ & \\
\hline
\end{tabular}

* These refer to the arbitrarily defined stratum corneum levels: the outermost 10-20 layers as level I, and the inner 20-30 layers as level II. 
TABLE V

Effect of Hydration on Griseofulvin Concentration on Palmar Stratum Corneum-Gloved Hand Experiment

\begin{tabular}{|c|c|c|c|c|c|c|c|}
\hline \multirow[b]{3}{*}{ Subject } & \multicolumn{6}{|c|}{ Gloved hand experiment } & \multirow{3}{*}{$\begin{array}{l}\text { Griseofulvi } \\
\text { glove }\end{array}$} \\
\hline & \multicolumn{3}{|c|}{ Control hand } & \multicolumn{3}{|c|}{ Gloved hand } & \\
\hline & $I^{*}$ & II* & III* & $I^{*}$ & $\mathrm{II}^{*}$ & III* & \\
\hline & \multicolumn{3}{|c|}{$n g / m g$} & \multicolumn{3}{|c|}{$n g / m g$} & $n g$ \\
\hline VN & 15.0 & 10.9 & $10: 3$ & 0.5 & 0.9 & 2.2 & NS \\
\hline MK & 28.9 & 20.6 & 9.5 & 7.3 & 6.1 & 6.2 & NS \\
\hline Co & 5.0 & 3.4 & 2.8 & 0.6 & 0.9 & 1.2 & NS \\
\hline $\mathrm{He}$ & 24.9 & 5.0 & & 6.1 & 、 2.8 & & NS \\
\hline Go & 39.4 & 6.6 & & 4.7 & 7.4 & & 300 \\
\hline $\mathrm{Ni}$ & 20.4 & 12.5 & & 6.9 & 3.7 & & 700 \\
\hline Po & 36.6 & 11.2 & & 3.9 & 2.2 & & 41 \\
\hline Mo & 21.1 & 4.6 & & 12.8 & 5.3 & & 120 \\
\hline $\operatorname{Tr}$ & 18.1 & 6.2 & & 6.7 & & & 71 \\
\hline $\operatorname{Mean} \pm \mathrm{SE}$ & $22.8 \pm 3.7$ & $9.5 \pm 1.9$ & $7.5 \pm 2.3$ & $3.88 \pm 1.15$ & $3.95 \pm 1.08$ & $3.2 \pm 1.5$ & \\
\hline
\end{tabular}

* These refer to the arbitrarily defined stratum corneum levels: the outermost 10-20 stratum corneal layers as level I, the intermediate 20-30 layers as level II, and the innermost 8-10 layers with stratum lucidum as level III.

occurs by passive diffusion through tissues and across sweat gland epithelium. This is thought to be somewhat analogous to kidney and glomerulous filtration apparatus, in that the nonprotein-bound drug (the free drug) represents the driving force for the passive diffusion through the cells into sweat gland fluids. Small molecules such as methylurea, thiourea, acetamide, and alcohol freely diffuse and rapidly equilibrate between plasma water and sweat water (7). Acidic or basic drugs appear in sweat according to the fraction of their molecules in the undissociated form (6). Johnson and Maibach have shown that the permeability of sweat gland epithelium is similar to that of other body membranes and have emphasized that, as with other systems, lipid solubility is a factor of prime importance in determining the rate of drug passage into sweat (8). Griseofulvin is a neutral molecule, but has a high lipid solubility and a high partition coefficient. One would anticipate, therefore, that it transfers into sweat readily. As discussed above, the plasma water concentration of griseofulvin can be estimated to be in the range of $150-450 \mathrm{ng} / \mathrm{ml}$; this will serve as an adequate driving force for passive diffusion into the sweat. The concentration formed in our sweat samples indicates that sweat may have equilibrated to the same concentration range as projected for plasma water (see Tables I and II).

The use of silicone hydrophobic resin to collect sweat proved a useful technique in collecting sweat for drug analysis with minimal surface contamination. The drug concentration found in control areas was $50-150 \mathrm{ng} / \mathrm{ml}$ higher than in the silicone-treated skin sites, which can be considered the amount of griseofulvin washed off the skin from that region by profuse sweating. In addition to the sweat mechanism, water is lost from the skin surface by transepidermal movement, which can contribute to the griseofulvin concentration in a complex fashion.

Our attempts to discern the relative fraction of griseofulvin supplied by sweat and by transepidermal cell water movement proved less successful. Although the topical dehydration experiment blocked delivery of sweat, as indicated by the iodine imprint method, the $40-60 \%$ fall in concentration of griseofulvin in stratum corneum can not be solely ascribed to sweat delivery, since the formaldehyde-releasing cream also tanned the outer cells and therefore probably interfered with transepidermal water loss as well. But maintenance of the reverse gradient, or wick effect, in treated stratum corneum indicates that transepidermal water loss may be a factor in delivering griseofulvin to the surface. Attempts to induce complete anhidrosis in subjects by administering an anticholinergic drug, glycopyrrolate, at doses of 16$20 \mathrm{mg} /$ day for 4 days, failed. Despite apparent virtual anhidrosis noted in both palms and soles by the starch iodine test at the time of scraping, griseofulvin levels were normal and nearly the same, whether the subjects were on or off the drug. However, since the drug was only administered during the day, it is possible that sweating resumed at night and delivered griseofulvin to the surface, since the subjects were exposed to relatively warm evening temperatures.

The occluded patch and gloved hand experiments were designed to prevent all water transfer through the skin by saturation of the outside environment. The results in Tables IV and $\mathrm{V}$ seem to confirm this concept. The gloved hand data are the more important; here a complete equilibrium seems to have been established in the 
gloved hand at all three levels, thereby removing the reversed gradient and strongly supporting the hypothesis that a wick effect is responsible for the observed reversed drug gradient within the stratum corneum.

\section{ACKNOWLEDGMENTS}

The authors wish to thank Ms. Lucy Roman and Ms. Francoise Mauray for their competent technical assistance.

This work was monitored by the Commission on $\mathrm{Cu}$ taneous Diseases of the Armed Forces Epidemiological Board and was supported by the United States Army Medical Research and Development Command under research contract no. DADA $17-69-\mathrm{C}-9170$; it was also supported in part by United States Public Health Service Grant NIGMS 16496.

This work was done at the California Medical Center Facility, Vacaville, Calif. (T. L. Clannon, M.D., Superintendent).

\section{REFERENCES}

1. Shah, V. P., S. Riegelman, and W. L. Epstein. 1972. Determination of griseofulvin in skin, plasma and sweat. J. Pharm. Sci. 61: 634.
2. Epstein, W. L., V. P. Shah, and S. Riegelman. 1972. Griseofulvin levels in stratum corneum. Study after eral administration in man. Arch. Dermatol. 106: 344.

3. Roth, F. J., Jr., and H. Blank. 1960. The bioassay of griseofulvin in human stratum corneum. , Arch. Dermatol. $81: 662$.

4. Harris, D. R., B. F. Polk and I. Willis. 1972. Evaluating sweat gland activity with imprint techniques. $J$. Invest. Dermatol. 58: 78.

5. Randall, W. C. 1946. Quantitation and regional distribution of sweat glands in man. J. Clin. Invest. $25: 761$.

6. Thaysen, J. H., and I. L. Schwartz. 1953. The permeability of human sweat glands to a series of sulfonamide compounds. J. Exp. Med. 98: 261.

7. Brusilow, S. W., and E. H. Gordes. 1966. The permeability of the sweat gland to nonelectrolytes. Am. J. Dis. Child. 112: 328 .

8. Johnson, H. L., and H. I. Maibach. 1971. Drug excretion in human eccrine sweat. J. Invest. Dermatol. 56: 182.

9. Vree, T. B., A. Th. J. M. Muskens, and J. M. van Rossum. 1972. Excretion of amphetamines in human sweat. Arch. Int. Pharmacodyn. Ther. 199: 311. 